\title{
Spontaneous recovery of a classically conditioned response by planarians'
}

F. T. CRAWFORD AND LARRY W. KING

FLORIDA STATE UNIVERSITY

Thirty flatworms, Cura foremanii, were classically conditioned with light and shock. Ss were given acquisition training of 20 trials a day for five days and then were divided into two matched groups. One group was given 40 extinction trials on day six. The other group was given 20 extinction trials on day six and 20 extinction trials on day seven. Spontaneous recovery of the response was demonstrated by significant differences between the groups as a result of the 24-hr. delay in extinction trials.

Recent experiments with planarians on response alternation (Lee, 1964; Shinkman \& Hertzler, 1964) and the distribution of practice on classically conditioned responses (Crawford, Livingston, \& King, 1966) may be interpreted as evidence for the frequently inferred underlying process of "inhibition." On the basis of these experiments it should be possible to observe other related phenomena. The present experiment was an attempt to produce spontaneous recovery of a classically conditioned response in planarians. Subjects

Ss of the experiment were 30 planarians, Cura foremanii, obtained from a commercial biological supply house. They were maintained individually in small plastic containers. Fresh spring water was changed daily. The experiment was conducted in an air conditioned room at approximately $22.2^{\circ} \mathrm{C}$ and $50 \%$ humidity.

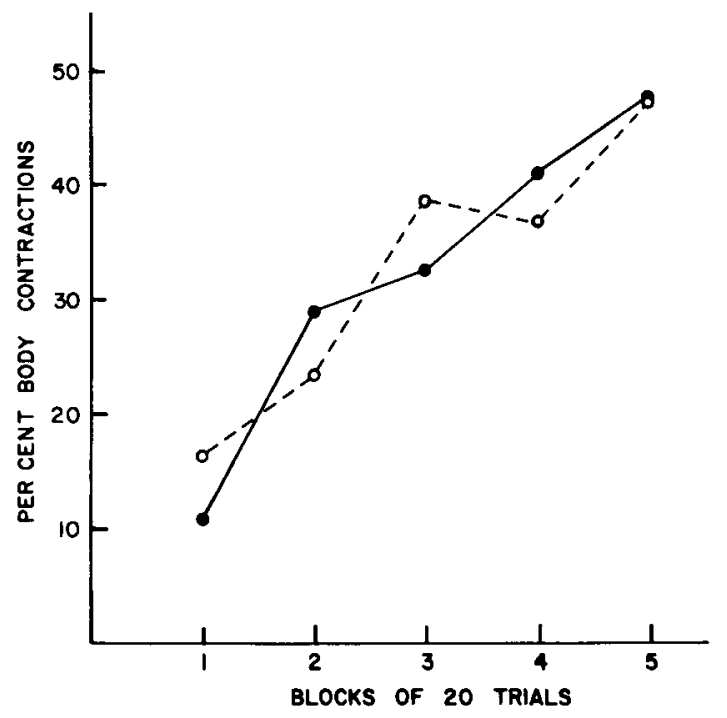

Fig. 1. Performance of the two matched groups during training.



Fig. 2. Performance of the group receiving 40 extinction trials on a single day (continuous line, closed circles) compared with that of the group receiving a $24 \mathrm{hr}$. interval between the first and last 20 extinction trials (discontinuous line, open circles).

\section{Apparatus}

Ss were trained in an apparatus essentially like that described by McConnell, Clay, \& Cornwell (1960). Two $100 \mathrm{w}$ lamps were located 9 in. above each of the troughs. Background illumination was provided by a 60 $\mathrm{w}$ bulb in a goose-necked lamp placed on the floor and directed into a corner of the room. The shock source was $30 \mathrm{v}$ ac with a $25 \mathrm{~K}$ ohm series resistance. A control box, small enough to fit into the hand, contained switches for presenting the light and shock. A running clock was used to time the stimulus events. Procedure

All Ss were given 20 light-shock presentations a day for five days. On each trial light was presented for 3 sec. with shock occurring concurrently during the final second. There was a minimum 60 sec. intertrial interval. The water in each trough was replaced with fresh spring water after each S's daily trials. Following acquisition training the Ss were divided into two groups matched for the frequency of body contractions during the initial $2 \mathrm{sec}$. of light presentation. On day six one group was given extinction training which consisted of 40 light presentations. The other group 
was given 20 light presentations on day six and 20 light presentations on day seven. The duration of light presentations and the intertrial interval for both groups was the same as that during acquisition training. Results and Discussion

The performance of the groups as matched following acquisition is shown in Fig. 1. It can be seen that the groups were highly similar to each other. The extinction data, in blocks of 10 trials, is shown in Fig. 2. The group receiving all extinction trials on day six demonstrates a progressive decline in percentage of body contractions whereas the group having a $24 \mathrm{hr}$. interval between the first and second 20 extinction trials shows a significant increase $(p<.001)$ in body contractions on the third block of 10 trials compared to the corresponding block of extinction trials in the other group. These results correspond to effects observed under similar circumstances in higher organ- isms frequently referred to as spontaneous recovery. The results may be interpreted as providing further evidence, therefore, of the congruence between behavioral modification in the flatworms and higher forms.

\section{References}

Crawford, F. T., Livingston, P. A., \& King, F. J. Distribution of practice in the classical condition of planarians. Psychon. Sci., $1966,4,29-30$.

Lee, $\mathbf{T}$. An investigation of alternation behavior under conditions of free and forced choice. Worm Runner's Digest, 1964, 6, 42.

McConnell, J. V., Comwell, P. R., \& Clay, M. An apparatus for conditioning planaria. Amer. J. Psychol., 1960, 73, 618-622. Shinkman, P. G., \& Hertzler, D. R. Maze alternation in the planarian, Nugesia tigrina. Psychon. Sci., 1964, 1, 407-408.

\section{Hote}

1. The research served as a partial fulfillment of the requirements for a MA degree in Psychology at Florida State University for the junior author (L.W.K.), conducted under the direction of the senior author (F.T.C.). 